\title{
Excavation control, management of blast damage, and quality control
}

\author{
J.V. Simmons Sherwood Geotechnical and Research Services, Australia
}

\begin{abstract}
Implementation of slope design transfers well-intentioned concepts, technical expertise, and cost commitments to a reality that cannot be fully or reliably predicted. With the uncovering of real geological and operational conditions come observations, actions, and experiences which may mandate changes to design for a multitude of reasons. Within the hierarchy of risk management actions, design is near the highest level of control, and approved design will include acceptance of geological and geotechnical uncertainties. Excavation, blasting, and quality control are aspects of design implementation where intention becomes confronted by reality; choices of action take place within a risk management framework in real time against a background that may be dominated by uncertainties.

Excavation control starts with consideration of survey methods and accuracy limits. Under some conditions, uncertainty in geometry may have a significant influence on outcomes of stability assessment, and this review offers a perspective based on risk management and quality control principles. When inspections are carried out it is necessary not just to identify materials, structure, and groundwater parameters but also to interpret and describe geotechnical behaviour type with respect to an accepted scheme that can guide risk management responses. An example is provided to illustrate the range of rock mass damage associated with different blast designs, with the view that blast damage can be more readily recognised and treated as a special case of excavation control. Quality control is discussed in terms of the gathering of evidence for updating estimates of likelihoods, and may range from simple visual inspection to complex, problem-driven measurements. Some examples are discussed and the overriding requirement to gather, check, and test evidence is emphasised. In conclusion, careful thought is required to resist the distorting aspects of modern communication tools on the timely communication of risk management information.
\end{abstract}

\section{$1 \quad$ Preventative and mitigating risk management controls}

Design is a creative process that starts with desires, concepts and ideas that become intentions. The design intentions are then transformed by means of costing constraints, technical skills, and applicable standards to outputs requiring documentation, communication, and approval. As the design process develops, a range of organisations and individuals with varying levels of ownership become invested in the outcome. The nature of those investments is transformed during the processes of implementation.

The most widely accepted framework for risk management is ISO 31000:2009 (International Organization for Standardization, 2009), which defines risk as 'effect of uncertainty on objectives'. Effects are defined as being either positive or negative deviations from the expected. Risk management controls are defined as the actions taken to modify risk. An outline of the ISO 31000:2009 risk management process is reproduced in Figure 1 to emphasise that, while we are typically absorbed with matters of detail, risk management extends from high-level intent, guidance, and communication to the most fundamental aspects of low-level task fulfilment.

For good reason, risk controls are focussed on potential adverse departures from design intentions, which we call hazards. Advantageous departures are, of course, agreeable bonuses measured as additional rewards. A widely-accepted and generally unattributed hierarchy of effectiveness of risk controls is shown in Figure 2; a version sourced from Quality Systems Pty Ltd (2013). In terms of risk controls, approved design is the outcome of engineering considerations which rank below, but should always include, due consideration of elimination and substitution. Approved design controls are preventative in nature. 
Implementation, the context of this paper, is guided by the approved design. Elimination and substitution are typically not possible during implementation, where the ranking of risk controls starts from engineering and works downwards. Importantly, controls during implementation range from preventative to mitigating.

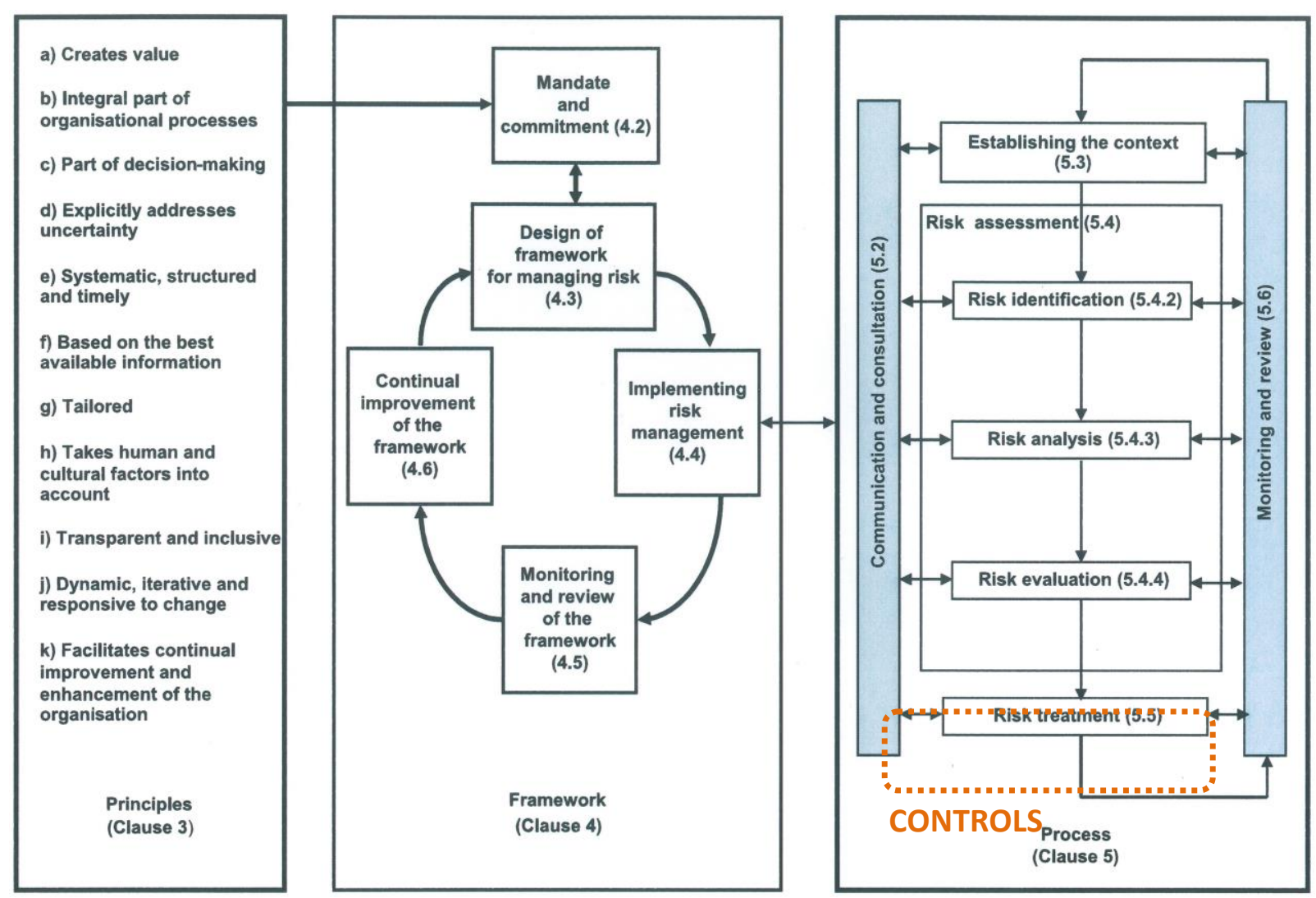

Figure 1 Relationships between risk management principles, framework, and process (after International Organization for Standardization, 2009 (ISO 31000:2009))

Implementation involves finite resources of equipment, personnel, and budget that are constrained by physical conditions, human capabilities and time. It should therefore be expected that implementation actions will experience hazards. Excavations that depart significantly from the intended design may present many types of hazards. Blast damage represents a particular class of hazards because both the design intent and implementation involve trade-offs, with effects that cannot be fully evaluated until exposure during excavation.

The methods by which hazardous circumstances are identified and their associated risks are controlled are dependent on how the outcome of excavations is measured. Different roles within a project may have very conflicting measures of success. For example, achieving high productivity for an excavator may be a bonus in terms of cost reduction and progress schedule. However, achieving high productivity by ignoring operating procedures that require intensive, low-productivity trimming of blast-damaged rock will create a rockfall hazard with high risks for exposed personnel and equipment, leading to cost blow-outs and schedule delays. In this review, quality control is discussed in terms of relationships to and interactions with risk management controls.

Quality control refers to the processes for measuring the success of an intended outcome, whereas quality assurance extends to demonstrating the effective functioning of the processes for achieving a successful intended outcome. Slope construction works will be undertaken under some form of quality management accreditation, usually traceable to ISO 9001:2008 (International Organization for Standardization, 2008) or equivalent, which describes the requirements for effective management of the system and processes which generate the intended outcome. 


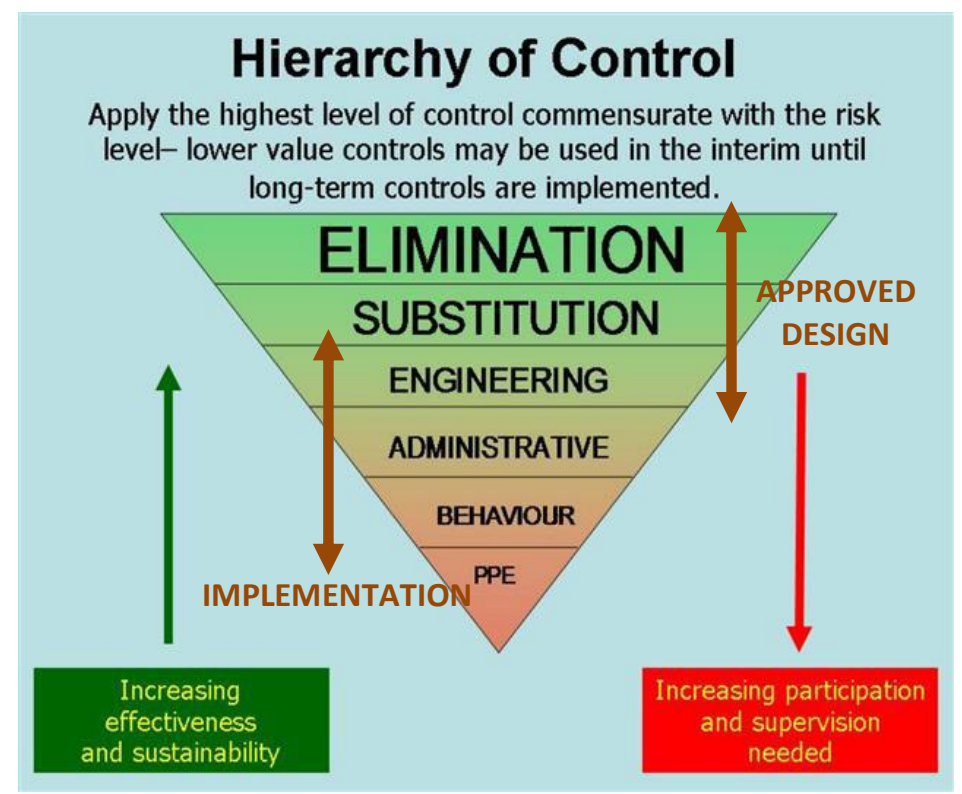

Figure 2 Hierarchy of risk management controls (adapted from Quality Systems Pty Ltd, 2013) (also described in Table 13.7 of Read and Stacey, 2009)

Busy practitioners are likely to experience some frustration with the administrative and documentation requirements of quality management systems. Furthermore, quality management of an implementation process will have different shades of meaning among individual practitioners, and different expressions of meaning among organisations. The discussion of quality control that follows herein is not concerned with the semantics of quality assurance, control, or management, but does refer to the hazards to which the design intent is exposed by some practical aspects of quality control. The author's view is that quality control during implementation of the approved design should not be viewed as a procession of activities each subject to individual analysis and authorisation, but rather as a complex process with a very simple goal: measures to achieve successful implementation of the design intent.

\section{$2 \quad$ Design documentation and ownership}

Irrespective of the design process details, implementation requires a description of the design intent which usually takes the form of drawings and a technical specification, together with an administrative framework. In the simplest of terms the 'drawing' may be a sketch or annotated photograph and the technical specification may be a verbal statement. For a complex project there will be volumes of drawings and the technical specification may comprise many interrelated documents. For the simplest project, the designer and specifier may also be the operator/constructor but most often there will be a distinct change of outcome ownership in the change from design to implementation. In complex and larger-scale projects, some design and documentation activities will be incomplete when other aspects have already been implemented.

Three aspects of quality management that are particularly relevant for slope construction contexts are:

- Effective documentation of slope geometry, traceable to agreed measurement standards.

- Effective control of documentation, so that the currently correct design details are implemented.

- Effective change management processes so that there is a common understanding of what is currently correct whenever a change occurs either to the design or to the construction activities.

There is an additional aspect which in the author's experience is usually implied but not always effectively communicated. Design is usually undertaken against a background of uncertainties, and all designs have inherent risk profiles. Unfortunately, design documentation does not always include a clear statement of assessed risks, risk treatments, controls, and proposed monitoring strategies. Management strategies for 
both the owner and constructor may include, through ignorance or deliberate intent, the clouding or understatement of risks and controls. The advantages and disadvantages of such strategies are usually related to commercial or personality issues and are not of concern here. What is of concern is that, no matter the context, a design risk assessment should exist and ideally will be explicit in the documentation of an approved design. As a separate matter, an implementation-stage risk assessment will inevitably be performed and will form the basis by which the risk controls for the implementation are managed.

Risk assessment is a familiar tool for practitioners, but unlike ISO 31000 there is no governing standard. Under ISO 31000 the frameworks for risk assessment are nationally circulated guidelines, e.g. Standards Australia, 2012, or either industry or organisation specific standards. In the slope engineering sector, irrespective of it being a civil or a mining project context, risk assessment is usually undertaken on a qualitative basis and most practitioners will be familiar with some form of consequence - likelihood matrix. Despite familiarity with such tools, not all practitioners realise that the basis by which levels of likelihoods and consequences are assessed, and the basis by which controls are determined, may all be more significant to a successful design implementation than the actual assessed level of risk.

Responsibility and accountability for implementing an approved design is described here as ownership. The owner of the implementation is generally not the designer, and the owner will usually have some authority to modify the design. A key feature of successful large-scale projects is an implementation management structure that encourages flexibility and rewards innovation, while maintaining the very clear commitment by the implementation owner to achieve the design intent. The actual designer may have a role in the implementation process as an advisor and technical contributor, but there can never be any question about who is responsible for managing the risks.

All of the above is a very simplified restatement of what may seem, to many managers, as very obvious. The author's experience is that most slope engineering practitioners are caught up in design matters, or implementation matters, but also in administrative tasks and the immediacy of electronic communications. When organisations struggle to provide clarity and respected leadership, it can be easy to lose track of the simplest quality management principle: that an approved design requires clear ownership of risk management during implementation.

\section{Excavation control hazards}

Each stage of an excavation is expected to happen according to plan and in accordance with the approved design. In the real world this may be the case most of the time, but it will definitely not be the case some of the time. The quality management documentation should be able to demonstrate the following:

- Adequately accurate and unambiguous survey for set-out and as-constructed geometry.

- Work undertaken in accordance with approved procedures and instructions.

- Either verification that the process was executed as designed; or

- Identification of the nature, extent, consequences, risks and controls following from non-conformance with design.

Appropriate quality controls should include measurements and observations of attributes where non-conformances might increase the level of or change the nature of assessed risks. These measurements and observations will constitute triggers for actions to mitigate the updated risks. Departures from the design intent, if identified, will be related to some combination of:

1. Slope geometry.

2. Geological materials and structure.

3. Groundwater conditions.

4. Geotechnical behaviour type. 
Unexpected blast damage may be considered as a special case of significant departures from the expected materials, structure, or geotechnical behaviour type.

\subsection{Hazards related to slope geometry}

Slope designs are generated from digital elevation models, geological models, and slope design shells. All are rendered as surfaces, from which the approved design geometry is generated. The approved design geometry is thus subject to the effects of measurement uncertainty associated with survey methods. Geometric discrepancies such as errors in batter angles may be visually obvious, but for most purposes post-excavation control checks require survey with associated measurement uncertainty. The magnitude of measurement uncertainty is directly related to the accuracy and potential errors of the survey method.

\subsubsection{Survey error and uncertainty}

Survey equipment must function correctly, be operated properly, and be loaded with the correct information referenced to control points whose coordinates are known and fixed within the project's adopted survey framework. While normally taken for granted, a 'fixed' mark on the Earth's surface may actually be moving at a rate of several $\mathrm{mm} /$ year due to effects of plate tectonics. All land management jurisdictions therefore adopt schemes for legally binding the locations of survey control points. Within the geometric extent of most projects, it is sufficient to measure locations relative to project control points.

Satellite-based methods now form the basis for location of control points. The most familiar terminology is the USA-developed Global Positioning System (GPS), with alternative systems being the Russian-developed GLONASS, the Chinese BDS or Compass, and the European Galileo. Civilian use of GPS requires enhancements, either by time-intensive static observations or the Real Time Kinematic (RTK) method in order to resolve locations to $0.010 \mathrm{~m}$ or less in the (local) horizontal plane and $0.020 \mathrm{~m}$ vertically. Within the past two decades RTK-GPS (or equivalent) has become the dominant survey tool of choice, but resolution of vertical location to $0.005 \mathrm{~m}$ or less still requires skilled operators using optical equipment, both of which are becoming increasingly rare. Total station (TS) optical survey techniques may be capable of finer horizontal and vertical resolution than satellite-based systems, but require considerably greater time and operator skill. Lin (2004) demonstrated the unambiguous speed and accuracy advantages of RTK-GPS compared with TS traverses of an urban area, with mean positional errors of $0.014 \pm 0.004 \mathrm{~m}$ and $0.163 \pm 0.063 \mathrm{~m}$ respectively. Kizil and Tisor (2011) reported variations of $-5 \%$ to $+15 \%$ when comparing calculated earthworks quantities for a diversion channel of defined section geometry to be excavated into triangulated surfaces generated from minimally-controlled RTK-GPS data of different areal densities, based on the 'correct' surface being generated from detailed TS data. Lee et al. (2013) demonstrated comparable accuracy of TS and RTK-GPS for surface definition of a large intertidal area, but with the latter providing much greater data density and both systems capable of resolving vertical position to within $\pm 0.012 \mathrm{~m}$.

Modern computer-based models represent as-designed and as-constructed surfaces by a mathematical fit to a grid of observation points that are referenced to control points. TS observation methods have now been largely superseded by terrestrial or aerial laser scanning (LiDAR), satellite-based radar (InSAR), or satellite-based stereoimaging methods. LiDAR scans typically generate point-clouds with much finer spacings than InSAR, and terrestrial LiDAR offers the greatest accuracy. Norheim et al. (2002) compared large-scale digital elevation models generated from InSAR and aerial LiDAR, with mean vertical errors of 0.500 and $0.269 \mathrm{~m}$ respectively and, significantly, InSAR being typically higher than LiDAR for concave surfaces but the reverse for convex surfaces. Novak and Baltsavias (2009) compared commercial satellite orthoimage products from several European providers, finding positioning differences in the horizontal plane of +0.040 to $-0.020 \mathrm{~m}$ in grid easting and -0.180 to $-0.600 \mathrm{~m}$ in grid northing. Arefi et al. (2009) reported median and mean errors of -0.230 and $-0.090 \mathrm{~m}$ in georeferenced digital elevation models for a complex scan area involving large differences and steep surfaces. By georeferencing LiDAR scans to minimal control points, generated by static GPS and having mean errors of $0.011 \mathrm{~m}$, Fowler and Kadatskiy (2011) reported mean positional errors of 0.004 to $0.006 \mathrm{~m}$ and 0.014 to $0.042 \mathrm{~m}$ for terrestrial and aerial LiDAR respectively. 
Slope engineering practitioners should therefore, based on the previously mentioned sampling of survey measurement uncertainties, expect unresolvable uncertainties in the order of $0.010 \mathrm{~m}$ or more for plan position, and $0.020 \mathrm{~m}$ or much more for vertical position. Without the application of systematic and detailed corrections to a spatially extensive grid of very accurate ground control points, errors in digital elevation models may be much greater. Haneberg (2008) described a study of urban landslide risk where the slope data were generated from a $1 \mathrm{~m}$ grid of aerial LiDAR observations. Elevation errors in comparison to a systematic network of 1,719 GPS control points depended weakly on slope angle and aspect, with a mean error of the order of $\pm 0.500 \mathrm{~m}$ and extreme errors ranging from -4.480 to $+3.320 \mathrm{~m}$. Monte Carlo simulations were used to evaluate the impact of the LiDAR errors on static Factor of Safety (FS) calculations, Newmark yield acceleration, and logarithmic Newmark displacements. Haneberg concluded that variations in FOS caused by geometric uncertainty were as significant as variations caused by shear strength uncertainty or pore pressure uncertainty.

\subsubsection{Detection of differences in excavated geometry}

Figures 3 and 4 show different sections through superimposed triangulations based on monthly LiDAR scans from an excavated face in a deep coal mine where signs of face instability had been visually observed and a range of additional movement monitoring actions had been implemented. The purpose of these figures is to illustrate the practicalities of interpreting survey information.

In both Figures 3 and 4 the sections were annotated on the basis of negligible variations in geometry resulting from the scanning process, relative to the scale of the slope. The farthest extent of the cracking from the crest is also marked with an arrow in each of the figures. On face value this may well be the case. Access restrictions were imposed because of significant surface cracking, so no significant work should have been undertaken within 20 to $50 \mathrm{~m}$ of the crest of the wall over the period between the two scans.

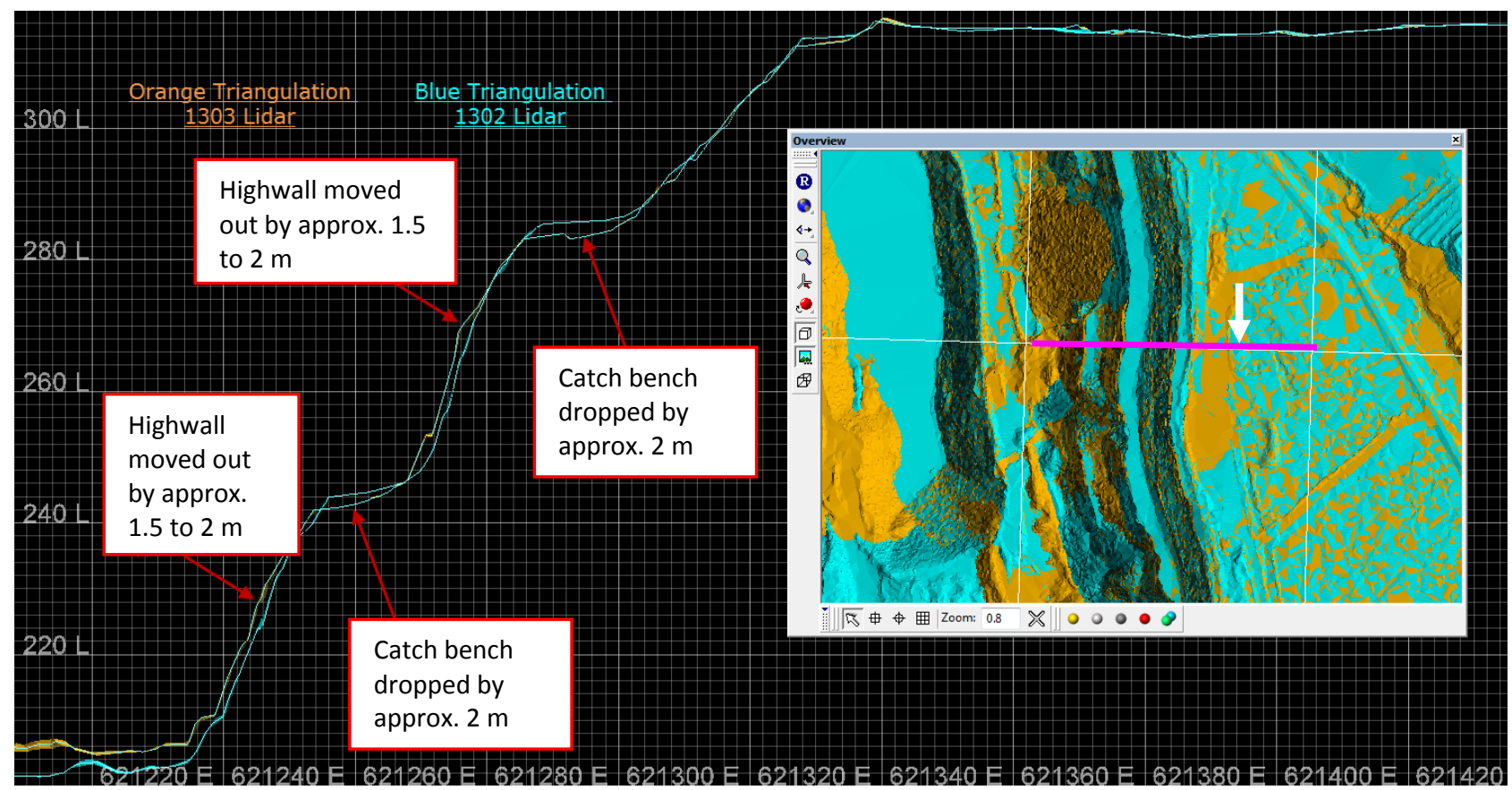

Figure 3 Example superimposition of monthly LiDAR scans for pit wall 'section A' with limit of cracking shown by arrow on section line (major gridline spacings are $20 \mathrm{~m}$ )

In Figure 3, there are no obvious discrepancies in the ground surface behind the crest, but apparent downward movement of benches combined with outward movement of batters in the order of $2 \mathrm{~m}$. Other methods of movement measurement had been deployed by the time these scans were made, and the generally confirmed apparent movements were 1 to $3 \mathrm{~m}$. At this location, negligible fretting of the batters was observed during the period of the scans. No explanation was forthcoming for the apparent buildup of 
material at the foot of the slope, approximately at $205 \mathrm{~L}$, as no mining activity occurred anywhere near the section at this level and fretting was minimal.

In Figure 4 however, there are obvious discrepancies in the ground surface behind the crest, for which no obvious explanation was available at the time. Apparent downward movement of the bench of between 1.5 and $2.0 \mathrm{~m}$ was partly consistent with measurements using other methods. Retreat of the batter between the 290 and the $260 \mathrm{~L}$ was attributed to fretting, but visual observations of fretting were more consistent with flattening of the batter rather than steepening. The buildup of talus material above the $250 \mathrm{~L}$ bench was consistent with fretting.

The approved design slope profiles for both of these sections are not shown, but when superimposed were found to generally conform within about $0.5 \mathrm{~m}$ or less to the 1,302 LiDAR scans. The exceptions were up to $3 \mathrm{~m}$ of crest loss on benches. From this perspective the use of survey scans, as shown in Figures 3 and 4 , is valuable evidence of excavated geometry and changes over time, provided that some attention is paid to resolving measurement method differences for which no visual confirmation is obvious.

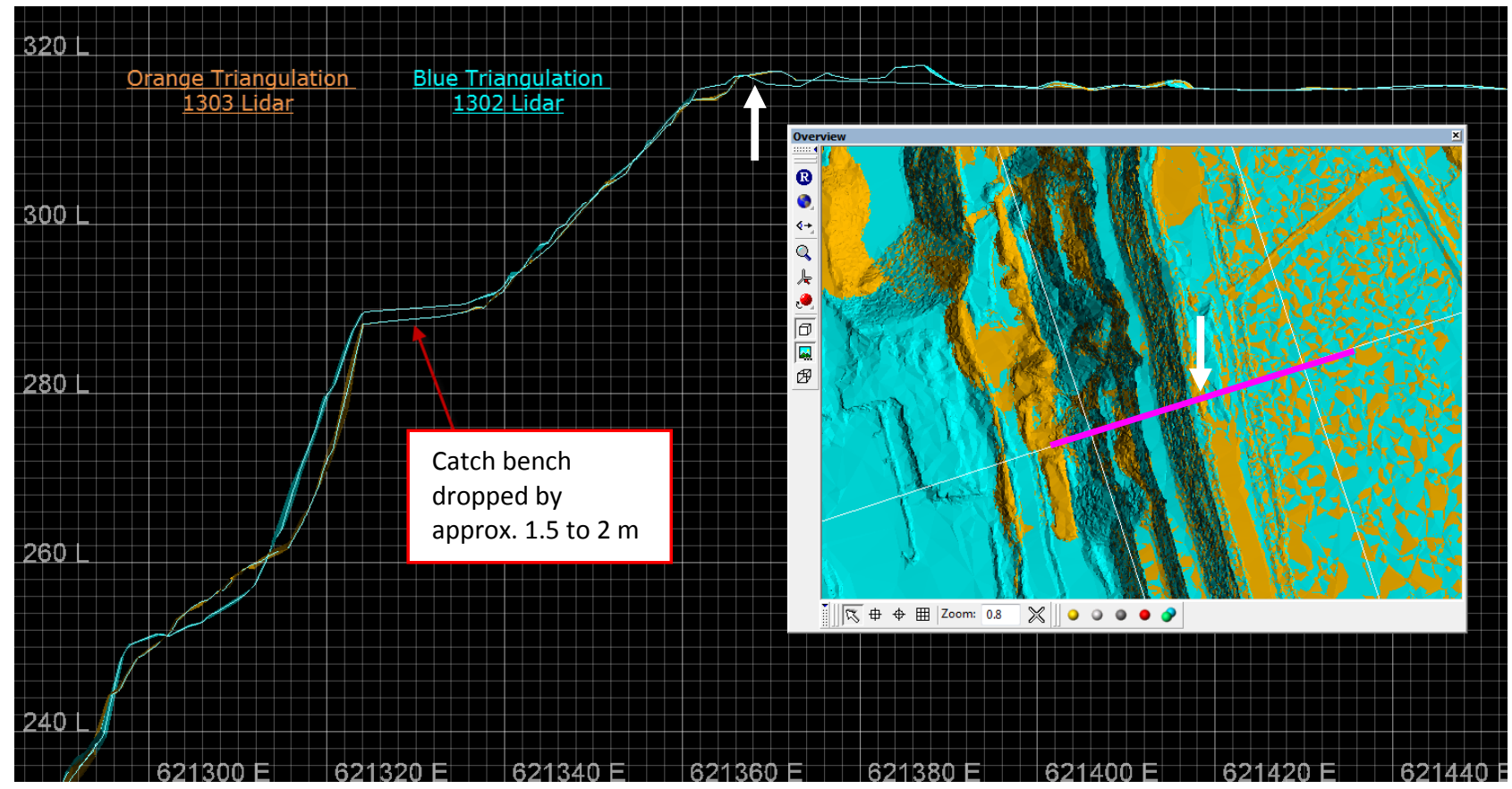

Figure 4 Example superimposition of monthly LiDAR scans for pit wall 'section B' with limit of cracking shown by arrow on section line (major gridline spacings are $20 \mathrm{~m}$ )

An obvious large-scale discrepancy between approved design and as-excavated slope profile is shown in Figure 5 from another coal mine. In this situation, an interramp angle of $45^{\circ}$ had been designed as a series of benches with $20 \mathrm{~m}$ vertical intervals and non-presplit $70^{\circ}$ batters. The geometric discrepancies should have been obvious to anyone involved in design or implementation, and there were significant rockfall hazards. The implementation errors were only formally identified when a different person was later tasked to prepare a pit design change, well after the excavation fleet had been deployed elsewhere and drilling below RL 1,440 was largely complete. A number of factors contributed to this discrepancy, including the scheduling, prioritising, and triangulations of the survey scan, lack of oversight within the design group, and lack of ownership within the operations group. This mine, like many others, had highly visible formal and informal processes for achieving production targets but no practical accountability processes for checking or controlling non-conformance with design.

This discussion of survey error and uncertainty has highlighted that practical accuracy is measured in terms of 5 to $10 \mathrm{~mm}$ or greater for most practical purposes. Such a limit is inconsequential for most civil or mining purposes, but errors greater than 50 to $100 \mathrm{~mm}$ start to be significant and differences of 500 to $1,000 \mathrm{~mm}$ should be obvious and rectifiable. 
The excavation control issues related to survey measurement are:

- No purpose is served by concern about survey measurement discrepancies that are of similar magnitude to the level of measurement uncertainty.

- When significant survey measurement discrepancies are identified, do they represent real changes or measurement errors, and if so which measurements were in error?

- What level of real, detected changes would amount to a significant increase to the assessed likelihood of an adverse slope stability outcome?

Best practice quality management systems will demonstrate that these issues have been considered and appropriate actions have been taken in a timely manner. This requires documentation: in reality the minimum standard should be personal diary notes of those concerned, with a summary written finding that can be readily referenced within the documentation system.

\subsubsection{Control of excavation using machine guidance}

The situation shown in Figure 5 arises where design controls are not effectively implemented, often by a workforce with little formal understanding of the design intent and the relationships between slope profiles and geotechnical instability hazards. Machine guidance, based on pre-programming of approved design geometry into a real-time guidance module on excavation equipment, provides an opportunity to minimise geometric errors. Several suppliers offer a range of guidance modules backed by highly integrated reporting systems with technical support services.

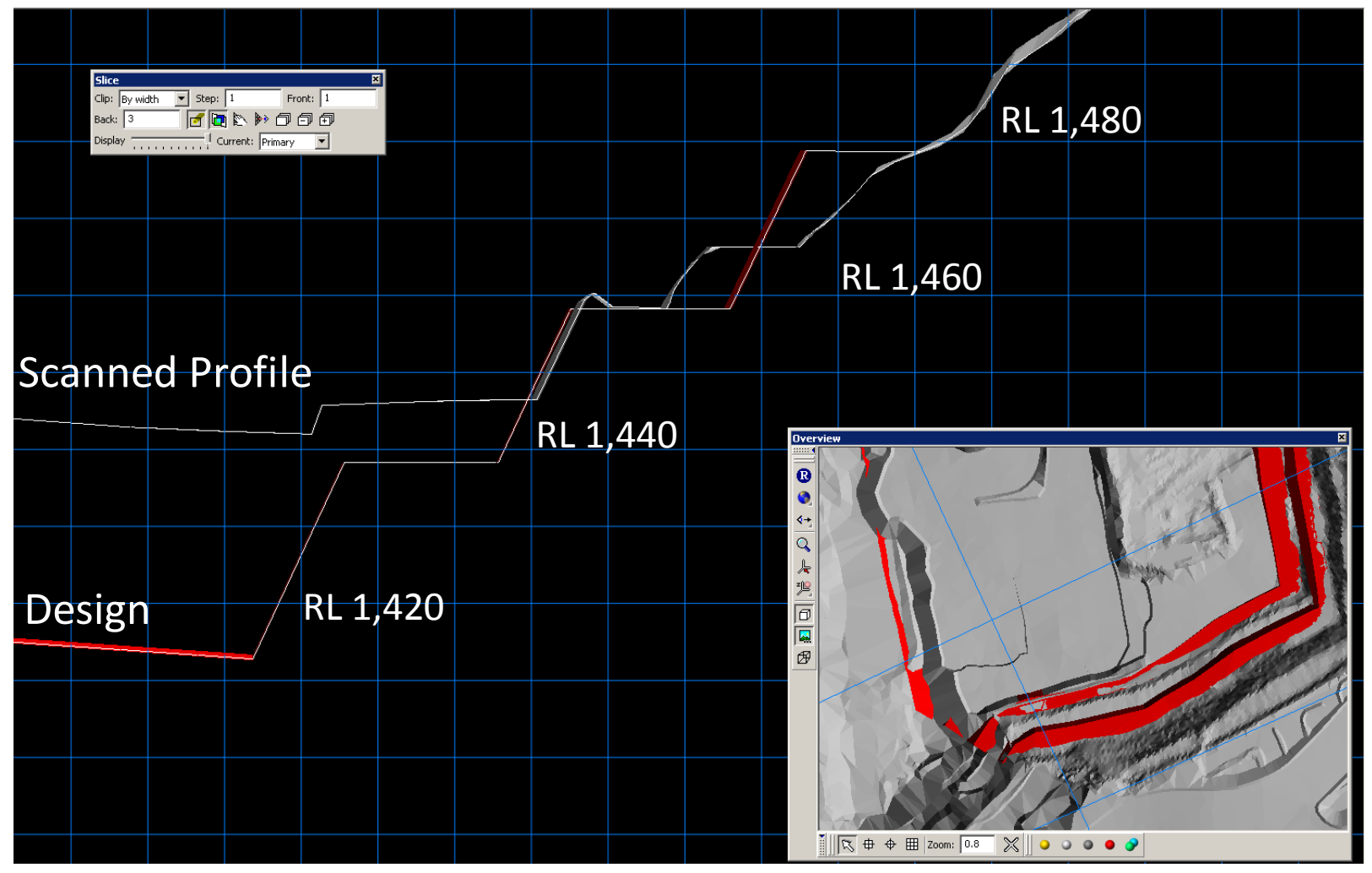

Figure 5 Example of an obvious discrepancy between approved design and as-excavated profile

It is not the intention of this paper to review the details of various commercially-available guidance systems. All such systems rely upon the following principles:

- Uploading to the machine of approved design geometry that is accurate enough for practical implementation. 
- Typically RTK-GPS location of the machine together with sufficient positioning sensors to provide a reliable measurement of the position and attitude of the machine's ground-engagement point.

- Real-time positional feedback to the operator that can be interpreted unambiguously and quickly enough to maintain optimum productivity of the machine.

- Training of the operator to follow the guidance system rather than relying on prior experience using visible markers or dead-reckoning.

- Component and system reliability of the guidance system that is at least comparable with the reliability of the machine, and at worst does not lead to significant loss of machine productivity.

- Collection and reporting of positioning and operational parameters so that the performance of the machine can be adequately monitored, supervised, and verified.

Given the above, it can be argued that such systems should perform optimally in the absence of interference or overriding actions by machine operators. Autonomous excavation systems with remotely located supervisory personnel are now under active consideration or implementation. Given that guidance and reporting systems are now used so widely, the relative lack of autonomous systems across the civil and mining sectors suggests that extensions of machine guidance to autonomous systems have not yet gained widespread acceptance.

In the author's experience, predominantly at open pit coal mining sites, argument against the value and acceptance of machine guidance relate to one or more of the following:

- Inadequate communication between designers and operators about intention of the design and of how it can best be implemented with available equipment capabilities.

- Inadequate operator training, sometimes extending to inadequate supervision.

- Scepticism on the part of operators or supervisors regarding the accuracy of intangible electronics, usually reinforced by confidence in manual and tactile skills, plus confidence based on earlier training in using visible markers such as pegs or batter-boards (matters of opinion about over-confidence and under-achievement of operators may also arise, but are not discussed here).

- Attitudes of some operators that the persons responsible for uploading approved design data into guidance systems, and/or the persons responsible for the approved design, do not have appropriate understanding of the issues involved in productive operation of the machine.

- Malfunctioning of mechatronics components, including invalid warnings from damaged, contaminated, or otherwise compromised sensors.

- Locally variable ground conditions, where the 'feel' of an experienced operator can work with the dynamic mechanical response of the machine in a manner that is far more sensitive, sophisticated and productive than the best current robotic control and feedback systems.

- Guidance systems that are too 'busy' for comfortable interaction with operators under the noise, vibration, visibility and communications constraints of a typical work environment.

- Operator concerns about conflicts between following a guidance screen while simultaneously, and effectively, monitoring the work environment by visual means for signs of unstable ground movement that could impact on personal and machine safety.

Obviously there will be circumstances where excavation errors occur due to operators simply ignoring whatever guidance is provided. The author is also aware of many circumstances where compliance with either visual markers or machine guidance systems has still resulted in serious discrepancies between approved design and actual excavation. These could almost always be tracked back to errors in survey, either in what was adopted for design or in what was set-out for implementation. Machine guidance systems and visual marker methods are equally reliant on appropriate survey accuracy and checking. 
Excavation control questions that could and should be checked and tested in relation to machine guidance include:

- Traceable records showing that accurate information was provided to the survey device or guidance module.

- Evidence that the provided guidance was being followed, or that acceptable alternatives were available and were being followed in the event of malfunctioning of the guidance system.

\subsection{Hazards related to exposure of geological and groundwater conditions}

Actual ground conditions remain unknown until exposed by excavation, but are expected to resemble the conditions that were assumed or adopted for the approved design. Natural variability should be expected, and also should have been given due consideration as part of the design process.

Inspections of exposed ground are required to either confirm compliance with the design conditions or to identify the nature and extent of non-compliance. In this context, 'inspection' refers to not only the physical task but also to reporting of findings. Inadequacies in the conduct of appropriate inspections, and inadequate timing of inspections, may both result in hazards of unrecognised conditions with consequences that may range from minimal inconvenience to catastrophic incidents. A more subtle class of hazards arises where an inspection process is undertaken but with practical inadequacies that are unrecognised. The majority of such inadequacies, in the author's opinion, relate to some combination of timing, qualification and experience, and effectiveness of reporting.

\subsubsection{Persons making inspections}

Because construction equipment causes observable interactions with the ground conditions, equipment operators are in effect undertaking a form of continuous inspection. Supervisory personnel are also regular witnesses, usually with the experience and judgement to recognise and categorise expected versus unexpected ground conditions. Operators and supervisors have the capability to record observations using a range of devices, and should be encouraged to do so within the agreed confidentiality limitations of the operation.

More formal inspections are carried out as required by project specialists with engineering or other scientific qualifications. The frequency and extent of such project inspections should be as flexible as possible but must also be defined so that there is a traceable accountability process. Timing issues may become particularly problematic where critical-path stages of a project include hold points with requirements for formal reporting and approval. Obviously the persons responsible for formal inspections must be suitably experienced.

The ideal inspection regime recognises all forms of observation and provides an organisational framework that encourages participation and communication at all levels of the workforce.

\subsubsection{Matters to be identified by inspection}

Very simply, inspection must aim to confirm compliance with or departure from the design intent. This requires adequate understanding of the design intent, adequate observational skills, and effective reporting techniques. As with all ground investigations, it is essential to separate observations from interpretations. For example, hand-penetrometer measurements or visual-tactile descriptions of observed material attributes are 'facts', whereas verbal onsite statements about stability of a batter or bearing capacity of a footing for temporary bracing are 'opinions'.

\subsubsection{Inspection methodology}

Inspection reports must be effective and this means that they must be meaningful to a wide range of people, and potentially in a wide range of settings. It is therefore essential that appropriate descriptive standards are used, that the persons making the inspections are adequately trained, that information is 
recorded in a meaningful way, and that the findings are clearly communicated. As an example, the CoalLog system (Larkin and Green, 2012; Simmons et al., 2013) has been developed for the Australian coal mining industry to use the most appropriate geological, geotechnical, and groundwater descriptive terms that are consistent with international or domestic standards, or in the case of rock substance strength are specifically developed to suit particular technical purposes.

Many different platforms are suitable for recording the observations and findings from inspections. Traditional formats range from paper sheets and checklists to fully electronic, automatically georeferenced GIS-based formats using combinations of pre-loaded maps, plans, and additions of notes (voice or text) and images (photographs or videos). Recording devices with voice activation are helpful for rapid and hands-free use in difficult worksite conditions. Whatever the technology, the best platform is that which provides the easiest method for completing the inspection (including reporting) task effectively under site conditions. Information to be gathered will answer any of the following as appropriate to the task:

1. Person or persons making the inspection, location, and time? These matters seem obvious but require conscientious recording for management purposes, and both personal and work-group accountability.

2. Geometry: how closely does it resemble the intended design? Survey-accuracy information may or may not be available at the time of inspection. The basis for any statement regarding geometric resemblance should be clearly recorded. It may or may not be possible to physically measure attributes such as batter angle and orientation. Any method(s) used should be clearly recorded. For quality control purposes, calibration and checking records relating to such methods must be suitably recorded and readily accessible.

3. Geological materials and structure: what observations? Descriptions must be professionally acceptable and consistent with an approved standard. This has many implications for record-keeping aspects of quality assurance and quality management. For example, observations of shear displacement, orientation, width, nature of apparently sheared materials, apparent throw and directional evidence of sheared surfaces should be recorded as evidence of a possible fault.

4. Geological materials and structure: what interpretations? The differences between observations and interpretations must be clearly understood by the observer. Geological training uses a framework of interpretation in many descriptive contexts, which may be helpful or harmful in a risk management context depending on whether the interpretation is correct or misleading. Using the above observations as an example, it may be possible to interpret the observations as a fault of a particular form. Equally, it may not be possible to interpret observations arising only from within a faulted zone as anything more specific than a sheared zone.

5. Groundwater conditions: what observations (if any)? Where? Is outflow water clear or clouded, in what way? Flow estimates or measurements should be recorded together with the method by which the information was obtained. For quality control purposes, calibration and checking records relating to such methods must be suitably recorded and readily accessible. Notably, the absence of any observations of groundwater should also be recorded, as this may be equally relevant for risk management purposes.

6. Geotechnical behaviour type? In contrast to the preceding matters, the geotechnical behaviour of the exposed material may not be clear, and an adequate interpretation may not be possible at the time of inspection. However, expected or predicted geotechnical behaviour is a key component of the design intent. A reasonable effort must therefore be made to interpret geotechnical behaviour at the time of inspection, and this aspect of the inspection may be the key finding in the report.

More detailed discussion of geotechnical behaviour type follows. The person(s) making such an interpretation must have appropriate qualifications, training, and experience to undertake the inspection. 


\subsection{Hazards related to geotechnical behaviour type}

Geotechnical behaviour refers to the expected response to excavation, for any geological material with any structure. The approved design should include due consideration of geotechnical behaviour type that will guide expectations during implementation. Will the exposed material behave as an unstructured or structured soil, as a structured rock mass, or as a rock substance with minor defects? How will groundwater conditions influence stability? Ideally this will be documented at the implementation stage, having been included in a design level risk assessment.

Recognition of behaviour type may be straightforward if instability occurs, but instability is not usually the design intent. It will require interpretation of the nature of potential instability hazards that should reasonably be expected given the nature of the materials, the scale of the slope, the role of groundwater, and the weathering effects over the timeframe of interest. Such interpretation must be made at the time and under the prevailing circumstances. Inadequate assessment, given the exposure that has occurred and the expected conditions for any future exposure, constitutes another hazard for the design intent.

In practice, the persons undertaking inspections may have no more than a rudimentary understanding of geotechnical behaviour or potential slope instability mechanisms. In the mining context, heavy reliance is placed on the experience of individuals, but there is a commonly-held fallacy that experience is measured in seniority, or quantities of time and projects rather than on a proven capability for testing observations against expectations to make useful interpretations. Similar reliance is probably made within the civil context with which the author is less familiar.

In the absence of project-specific definitions and documentation or adequate training and experience, the Cruden and Varnes (1996) framework is a suitable guide to the range of slope instability processes. It is equally applicable to natural and constructed slopes and involves the following attributes:

1. Type: fall, topple, slide, spread, or flow (Figure 6).

2. Material: rock or soil (soil may be subdivided into Earth (finer-grained, cohesive) or debris (coarser-grained, granular).

3. Water content: dry, moist, wet, very wet.

4. Rate: extremely rapid, very rapid, rapid, moderate, slow, very slow, or extremely slow (Figure 7).

The Cruden and Varnes framework is backed by referenced experiences for the different types and rates of slope instability. Currently Cruden (pers. comm.) is considering whether the so-called composite collapse mechanism for bedded rock masses, described by Simmons and Simpson $(2006,2007)$, should be added to the list of types. Under the current framework, composite collapse can be best described as a complex combination of fall, topple, and slide that initiates by propagation of brittle extensional fracturing through rock bridges within a blocky mass, resulting in sudden (minimal visually-detectable precursor movement) and rapid (velocity class 7) collapse. Adequate warning of composite collapse is of particular concern to personnel and equipment working within the potential runout zone at the toe of a slope. Visual detection cannot be considered as a reliable control because initial movements are so small and the mechanisms leading to instability are not yet well understood. Predictions of collapse based on stability analyses with estimated rock mass strengths are usually too uncertain, leaving fine-movement measurement techniques such as radar or extensometers as the preferred monitoring method.

Cruden and Varnes also included information from historical events associating the velocity of instability with vulnerability of exposed people, and associating the volume of instability with travel or runout distances. In the author's experience, lack of informed consideration of geotechnical behaviour type in relation to potential slope instability processes is still widespread, and continues to result in 'unexpected' instability hazards with volumes, movement rates, and travel distances that were reasonably foreseeable. 
(a)

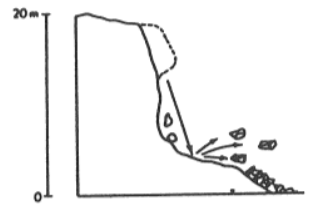

(b)

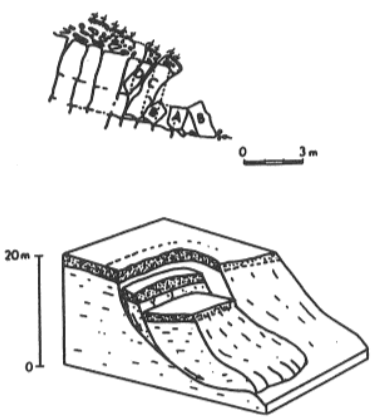

(d)

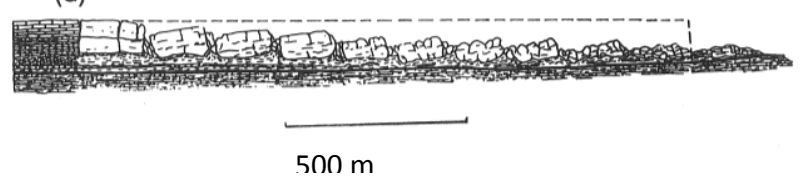

(e)

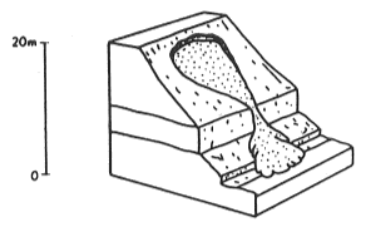

Figure 6 Landslide type; (a) fall; (b) topple; (c) slide; (d) spread; (e) flow (after Cruden and Varnes, 1996)

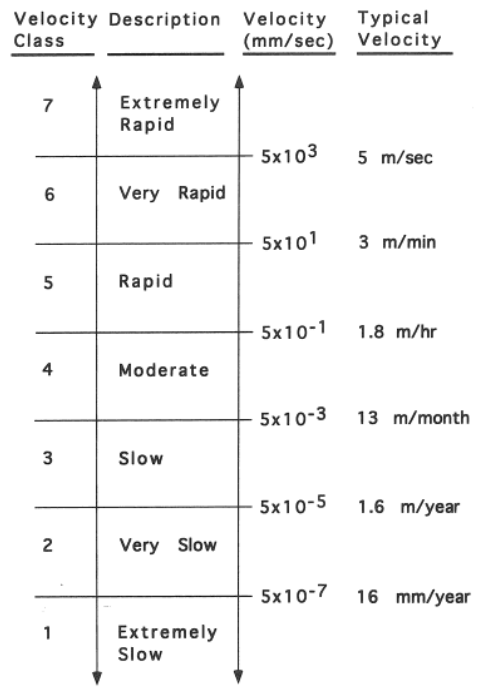

Figure 7 Recommended landslide velocity classes (after Cruden and Varnes, 1996)

A perceived limitation of the framework relates to the design life of a constructed slope for a civil or a mining purpose, as distinct from the time-scales that apply to geomorphological evolution of natural landscape features. Geotechnical behaviour type is as relevant to immediate, temporary events such as exposure of an unsupported panel to enable installation of ground support as it is to a strip highwall in a coal mine, or to long-term scenarios such as the final wall of a metalliferous pit with potentially indefinite 
post-closure exposure. Provided that the effects of time on geotechnical behaviour type are reasonably understood, appropriate consideration can be given to the effects of time on slope performance.

\section{$4 \quad$ Management of blast damage}

Blast damage to the surrounding rock mass is an inevitable consequence of blasting. Williams et al. (2009) provide extensive information about controlled blasting while Scott (1996) devote chapters 8 and 9 to fragmentation and near-field damage and wall control, respectively. Most geotechnical practitioners have little training in blast design and minimal exposure to the practicalities of blast implementation. This gives rise to a fundamental geotechnical challenge: the recognition of and allowances that should be made for blast damage as distinct from natural geological structure when inspecting a slope that is subjected to blasting.

Blast fracturing mechanisms depend on the nature of the explosive, the nature of the rock mass, and the physics of the explosion processes. Many variables are involved, and there are compromises between achieving effective fragmentation and minimising damage to surrounding material. Even a simplified understanding of damage mechanisms should nevertheless consider the following:

- Detonation generates high-temperature, high-pressure gas which typically crushes rock material within $2-3$ charge diameters of the blasthole wall.

- A radially-directed compressive strain pulse with a concurrent hoop strain propagates beyond the crush zone, typically generating radially-directed tensile fractures for 20-30 blasthole diameters.

- Reflection off a rock-air or rock-water interface generates a reflected tensile strain pulse which can cause spalling fractures at and for some distance behind the interface.

- Crushing, fracturing, and attenuation of strain pulses consume energy and so limit the extent of fracturing, but attenuation processes may include slip on interfaces, resulting in loosening of the rock mass beyond the fracture limit.

Many techniques are used to limit the extent and nature of blast damage. Within the Australian metalliferous mining industry the use of trim blasts, with or without presplits, is common. Within the Australian coal mining industry trim blasts are generally avoided or not executed well, but presplits are common. The Australian civil construction sector generally executes highly effective presplits, probably because of small diameter closely spaced blastholes, limited blast panel dimensions, and limited charge magnitudes.

The objective of a presplit may appear straightforward but design and execution are far from simple. Outcomes from presplits may therefore be highly variable, even within a single mining operation. The intention of presplitting is to minimise the crushed zone, create a single fracture linking to the blastholes to either side, and avoid the damage associated with gas confinement. When presplits are stemmed to comply with noise-limitation requirements there is inevitably some general fracturing in the stemming zone with resulting loss of crestlines and loosened bench edges, resulting in elevated rockfall risks for subsequent work below. A midsplit is a modified form of presplit, where the presplit line is fired as the first step of a production or trim blast. While this is efficient from a drill scheduling viewpoint, there is a much greater likelihood of choking and the intended split fracture is usually more ragged.

A long presplit is typically fired as a set of panels with short delays between panels to reduce ground vibrations. The direction of firing should be set from structural geological considerations. Using the convention of free face to the right, the direction of firing of successive presplit panels should intersect the dominant joint direction at an acute angle to the right, so that any gas pressure wave will tend to open these joints towards the free face. If the opposite firing direction is used, gas-jacking will create a saw-tooth pattern of loosened blocks behind the subsequent wall crest.

In the mining industry, accountability for drill and blast performance is typically related to effective production and minimised dilution. Accountability for detection and definition of blast damage is typically 
related to excavation control for geotechnical hazard management purposes. Often these two accountabilities do not overlap. Furthermore, most site personnel do not have the skills to objectively observe and map geological structure, so recognising the nature and extent of blast damage on an exposed face may or may not be a simple or straightforward task.

Figure 8 shows a sequence of three excavated faces that were directly adjacent to one another and where three different blast methodologies were used. These three views, of essentially the same geological materials and structure, graphically demonstrate the relative effects of blast damage associated with: (a) no face control (b) midsplitting and (c) presplitting. Each of the three faces was excavated back to a hard surface using the same equipment, operators, and operating procedures.

Figure 8(a) shows the typically irregular finish defined by uncontrolled blast fracture damage which is more pronounced within the upper blocky higher-strength sandstone in comparison to the lower-strength interbedded siltstone-sandstone units lower in the sequence. This is a predictable outcome of several well-established principles of blasting theory and practice. The wall profile is irregular, controlled to some degree by the joint development and spacings, and has a 'hard toe' where the blast loading within the interburden between the two seams was modified to limit damage to coal but this resulted in ineffective fragmentation. Despite being hard-dug, this face has numerous locations where loosened or laterally unrestrained noses imply a much higher likelihood of rockfall hazards involving large blocks.

Figure 8 (b) shows a typical better-than-average midsplit outcome, with a relatively regular large scale finish but noticeable smaller-scale roughness attributable to penetration of blast fractures behind the design split line. The amplitude of the smaller-scale roughness is proportional to the spacing and continuity of the natural joints. The quantity and maximum particle size of the debris rill at the toe of the face is a measure of the amount of loosened material which has fallen since excavation, and therefore proportional to the amount of blast damage at the wall face.

Figure 8 (c) shows a high quality through-seam presplit outcome. Apart from backbreak where a shear zone traverses the face, half-barrel traces are evident from close to the crest down to floor level. There is a hint of 'hang-up' within the interburden, again attributable to limiting the blast loading to limit damage to coal. It is notable that the split line did not span directly between every presplit blasthole, but the local irregularities still constitute a hard, relatively undamaged face as evidenced by the general lack of rilled debris at the toe. There is one area of rilled blocky material, consisting of fallen 'hang-up' material. Rockfalls of such limited nature have a very low risk rating due to the standard operating procedures which are an essential component of the risk controls for working at the toe of excavated walls.

The examples of Figure 8 provide a graphical illustration of the expectable effects of 'routine' blast damage on excavated faces. However, blast damage can take many other forms besides those illustrated in the figure. Management options are relatively simple: either remove all loosened material, or make a realistic assessment of volumes and runout zones and provide adequate catch controls at the toe of the slope.

\section{$5 \quad$ Quality control}

\subsection{Underlying purpose}

Collection of performance information is an essential element of quality management. However, the underlying purpose of quality control is to provide evidence for making informed decisions about risks. The evidence may take many forms, depending on the nature of the assessed risks. Evidence must first be checked: does it make sense, is it consistent with other evidence, does it provide information that can be tested for updating estimates of likelihood and consequence? After the evidence has been checked it should be tested against the existing risk controls.

Slope engineering practitioners should be familiar with qualitative consequence-likelihood matrix methods for measuring risk. Experience and reasoned judgement are required to measure consequence. Kahneman (2011) clearly explained the critical significance of not relying on personal instinct or recollections because 
rapid, immediate and decisive thoughts can be subject to subconscious and undetectable bias. By contrasting the advantages and disadvantages of fast and slow modes of thinking, Kahneman showed why a more analytical and thoughtful approach is necessary to test the true nature of evidence against interpretations. 

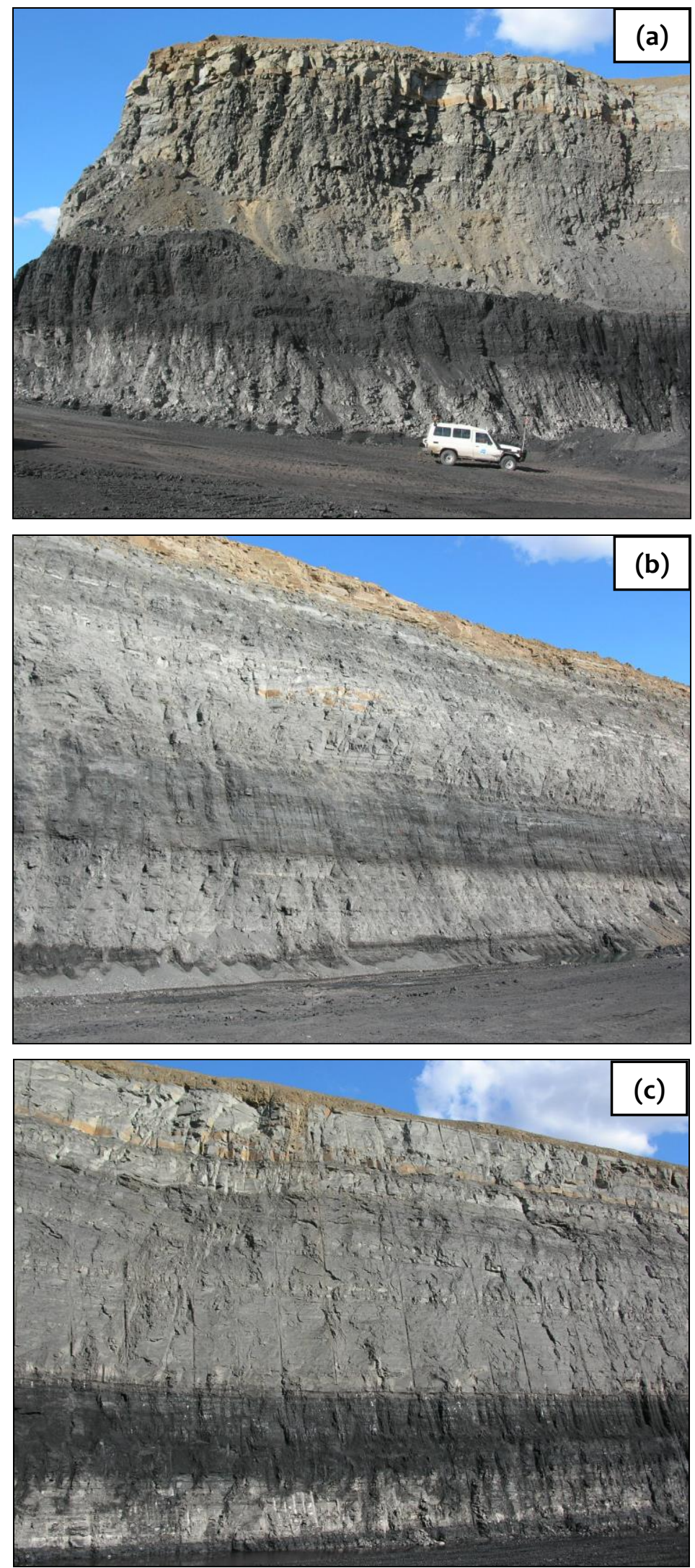

Figure 8 Comparison of faces with; (a) no controlled blasting (endwall, looking north); (b) midsplit; and (c) presplit, (high walls to north and south of endwall respectively, looking east) 
Likelihoods are generally subjective assessments of probability, and in principle are amenable to updating using the techniques of Bayesian inference. In current slope management practice such a formal approach is rarely practical, but it should not be neglected for future research and development in the era of fast, semi-automated processing of large datasets obtained from smart sensors, scanners, and radars. Quantitative probabilistic assessment of the likelihood of instability based on geotechnical analysis is only notionally practical, because the variabilities of geometric inputs are usually ignored due to the computationally intractable levels of simulation that are generally required.

The author believes that the principal justification for expending resources for quality control is to gather evidence that can test whether or not a prior estimate of likelihood has changed. If and when likelihoods change, then certain actions may be required in order to seek acceptable levels of risk. Also, when the likelihoods of certain consequences change, other consequences may become more significant and require risk controls.

The examples described below are intended to illustrate a range of quality control processes and to comment on some pitfalls that can arise when quality control is confused with quality management.

\subsection{Routine visual inspection scenarios}

Minimal quality control effort can be justified under normal and routine circumstances where designs and implementation procedures are effective. There are three considerations for what that minimal effort should comprise:

1. If significant risks are identified, appropriate notifications including awareness of additional controls must be communicated in an effective and timely manner.

2. Information from the check should be meaningful and able to be interpreted by others.

3. Satisfying the requirements of an auditable, accredited quality management system for records demonstrating that someone checked, and that the outcome of the check was given due consideration.

Some inspection personnel will have geological training but many will have only rudimentary geological knowledge, and most will have limited geotechnical skills or experience. For this reason, checklist systems can by breaking down complex considerations into observable or measurable items which can be combined in some manner to provide a relative ranking of risk.

Hoelle and Canbulat (2012) described the checklist process implemented by Anglo American at its Australian open cut coal mines to capture expert judgements about slope risks. Observations of excavated walls require the observer to score two classes of parameters:

1. Those that cannot be varied for a particular location: geology, water, spontaneous combustion, and dragline bench material.

2. Those that can be varied or controlled at that location: geometry, mining and blasting.

Figure 9 shows the scoring system for the variable parameters. Based on expert opinion about contributions to risk, weighting factors are assigned to generate the overall risk rank. The parameters which provide the greatest contributions are highlighted, and suggested risk controls are provided. If there are any weaknesses in this particular system, these would be the over-simplified treatment of geological structure and, by association, under-recognition of geotechnical behaviour type to be expected.

Similar geotechnical parameter scoring systems have been developed for civil engineering slope risk assessment purposes, and are particularly helpful for prioritising controls and remediation actions. Within Australia, the Roads and Traffic Authority (RTA) slope risk assessment process has been widely adopted, referenced, and updated since its initial publication (Stewart et al., 2002). In contrast to checklists from the mining sector, civil ranking systems are intended for use by persons with training in engineering geology and are therefore more technical in presentation and content. 


\begin{tabular}{|c|c|c|c|c|c|c|}
\hline \multicolumn{3}{|c|}{ 1) GEOLOGY } & & \multirow{5}{*}{1.10} & Highwall condition & \\
\hline \multirow{5}{*}{1.1} & \multicolumn{2}{|l|}{ Depth of weathering } & & & Stable & 1 \\
\hline & \multicolumn{2}{|l|}{$0.5 \mathrm{~m}$} & 1 & & Loose/rock/blocks & 5 \\
\hline & \multicolumn{2}{|l|}{$5-10 \mathrm{~m}$} & 5 & & Wedges/overhangs & 10 \\
\hline & \multicolumn{2}{|l|}{$10-20 \mathrm{~m}$} & 10 & & Zone of weakness & 20 \\
\hline & \multicolumn{2}{|l|}{$>20 \mathrm{~m}$} & 20 & \multicolumn{3}{|c|}{ 2) WATER } \\
\hline \multirow{5}{*}{1.2} & \multicolumn{2}{|l|}{ Discontinuities } & & & Water coming out of face bedding or structu & \\
\hline & None & & 1 & 2.1 & NO & 1 \\
\hline & 1 (simple) & & 10 & & YES & 10 \\
\hline & 2 (complex) & & 10 & & Is there water accumulation at toe of slope & \\
\hline & $\geq 3$ (complex) & & 20 & 2.2 & NO & 1 \\
\hline & Direction of discontinuities & & & & YES & 10 \\
\hline 13 & Not applicable & & 1 & & Is there water on top of highwall/benches witt & of crest \\
\hline 7.3 & Same direction (<30 deg.) & & 10 & 2.3 & NO & 1 \\
\hline & Different direction $(>30$ deg. $)$ & & 20 & & YES & 10 \\
\hline & Dipping structure / bedding & & & & Rain & \\
\hline 1.4 & Flat/dipping into the face & & 1 & 24 & No rain in past 5 days & 1 \\
\hline & Dipping into the cut & & 20 & 2.4 & Rained in the past 5 days & 5 \\
\hline & Clay material in bedding & & & & Has been raining for the past 5 days & 10 \\
\hline 1.5 & NO & & 1 & & Head of water & \\
\hline & YES & & 10 & 25 & No water & 1 \\
\hline & Length of structure & & & 2.5 & Stable, no increase & 5 \\
\hline 16 & $0.1 \mathrm{~m}$ & & 1 & & Increase in water head & 10 \\
\hline 1.6 & $1-5 \mathrm{~m}$ & & 10 & & 3) SPONCOM & \\
\hline & $>5 \mathrm{~m}$ & & 20 & & Is the toe of highwall burning & \\
\hline & Presence of floor rolls and dippings & & & 3.1 & NO & 1 \\
\hline 1.7 & NO & & 1 & & YES & 10 \\
\hline & YES & & 10 & & Is the toe of lowwall/spoil or any layer burni & \\
\hline & Major dykes/faults/burnt coal & & & 3.2 & NO & 1 \\
\hline 1.8 & NO & & 1 & & YES & 10 \\
\hline & YES & & 10 & & 4) DRAGLINE & \\
\hline & Cracks on highwall/benches within $10 \mathrm{~m}$ & & & & Dragline bench built on & \\
\hline 1.9 & NO & & 1 & & Not applicable (truck \& shovel operation) & 0 \\
\hline & YES & & 20 & 4.1 & Unweathered material & 1 \\
\hline & & & & & Weathered material & 5 \\
\hline & & & & & Weathered material and water & 10 \\
\hline & 1) GEOMETRY & & & & Noses present & \\
\hline & Batter back soft/weathered material & & 1.8 & & NO & 1 \\
\hline 11 & Not Applicable & 1 & & & YES & 20 \\
\hline 1.1 & Yes / minimum 50 deg. & 10 & & & Loose blocks at crest & \\
\hline & No / more than $50 \mathrm{deg}$. & 20 & 1.9 & & NO & 1 \\
\hline & Height of highwall & & & & YES & 20 \\
\hline & $0-35 \mathrm{~m}$ & 1 & & & 2) MINING & \\
\hline 1.2 & $35-50 \mathrm{~m}$ & 5 & & & Undercutting spoils & \\
\hline & $50-70 \mathrm{~m}$ & 10 & 2.1 & & NO & 1 \\
\hline & $>70 \mathrm{~m}$ & 20 & & & YES & 20 \\
\hline & Angle of highwall & & & & Undercutting highwall & \\
\hline 13 & $<65$ deg. & 1 & 2.2 & & NO & 1 \\
\hline 1.3 & $65-75 \mathrm{deg}$. & 5 & & & YES & 20 \\
\hline & $>75 \mathrm{deg}$. & 10 & & & Spoils in water & \\
\hline & Top bench width & & 2.3 & & NO & 1 \\
\hline 14 & $>10 \mathrm{~m}$ & 1 & & & YES & 10 \\
\hline 1.4 & $0-10 \mathrm{~m}$ & 5 & & & ing of weathered material at toe of spoils & \\
\hline & No bench & 10 & 2.4 & & NO & 1 \\
\hline & Spoils on the highwall & & & & YES & 10 \\
\hline & Not applicable & 0 & & & 3) BLASTING & \\
\hline 15 & $<15 \mathrm{~m}$ high $/>10 \mathrm{~m}$ from crest & 1 & & & Blasting method of highwall & \\
\hline 1.5 & $<15 \mathrm{~m}$ high $/<10 \mathrm{~m}$ from crest & 3 & 3.1 & & Pre-split & 1 \\
\hline & $>15 \mathrm{~m}$ high $/>10 \mathrm{~m}$ from crest & 5 & & & No pre-split & 10 \\
\hline & $>15 \mathrm{~m} \mathrm{high} /<10 \mathrm{~m}$ from crest & 10 & & & Highwall condition due to blasting & \\
\hline & Height of spoils on lowwall & & 90 & & Straight $\mathrm{H} / \mathrm{W}$ no loose material & 1 \\
\hline & Not applicable & 0 & 3.2 & & Straight highwall, some loose material & 5 \\
\hline 1.6 & $0-40 \mathrm{~m}$ & 1 & & & Frozen coal, overhangs, loose material & 10 \\
\hline & $40-95 \mathrm{~m}$ & 5 & & & Pre-split barrels & \\
\hline & $>95 \mathrm{~m}$ & 10 & 39 & & Not applicable & 0 \\
\hline & Cut width (deviation from standard) & & 3.3 & & Visible & 1 \\
\hline 1.7 & Standard within $5 \mathrm{~m}$ & 1 & & & Not visible & 10 \\
\hline & Not standard ( $>5 \mathrm{~m}$ deviation) & 10 & & & Blast holes & \\
\hline & & & 3.4 & & Visible & 1 \\
\hline & & & & & Not Visible & 10 \\
\hline
\end{tabular}

Figure 9 Open pit coal mine excavated wall geotechnical risk ranking parameters (after Hoelle and Canbulat, 2012; Canbulat et al, 2013) 
The author has been involved in the development and use of geotechnical checklists for open pit coal mining purposes for nearly two decades, and has seen an increasing uptake of such methods for reporting purposes. 'Tick and flick' records that are filed are comparatively ineffective. Checklists that readily highlight hazardous features with high risk rankings, and require control actions to be reported can be very effective, particularly when displayed in work crew muster areas. The common denominator for highly effective routine visual inspections is a simple and graphic message to the people who are exposed showing what the hazard looks like, what controls are required, and the risk rankings before and after controls are implemented.

\subsection{Project-critical high risk scenarios}

Best practice quality management aims for the best outcome while planning for the worst outcome. Occasionally, and for the widest possible range of reasons, high risk circumstances arise that have the potential to catastrophically impact a project. Catastrophic consequences are inevitably ranked at the highest level of risk, due to their combination with often unpredictably low likelihoods of a chain of events that may not be reasonably foreseeable. Rather than describe generalities, an example scenario is described in order to demonstrate the roles of quality control activities.

A deep open pit mine slope excavation exposed expected geological materials and major faults, but the rock mass between some faults was much more intensely blocky than elsewhere. As excavation progressed deeper, isolated rockfalls from the blocky zone became more frequent and involved larger volumes, generating high risks for project-critical work on the benches below. Cracking behind the crest propagated and radar measurements detected significant movements between the faults after a severe rainfall event. It was debatable whether identified blast damage was pre-conditioned blockiness or blast-generated. The underlying hazard to the project was the instability of the excavated slope, but the geotechnical behaviour type was either a continuation of potentially controllable rockfalls or progressive development of a large scale deep-seated and highly mobile collapse. The nature of the consequences was therefore uncertain.

Approved design was based on a modest quantity of geotechnical design data from observation wells, face mapping, cored boreholes with geophysical logs and ATV imaging, plus precedent experience from an adjacent excavation. Consequences were modelled and likelihoods evaluated by kinematic assessment of defect orientation data, 2D limit equilibrium analysis, and 3D deformation modelling. Geotechnical and hydrogeological models and the slope profile design were peer reviewed prior to project approval. A range of controls for detecting and responding to unplanned movement or instability were identified at the design stage and were progressively implemented. These included regular visual inspections, continuous radar scanning, TS prism surveys, regular LiDAR scans, and multiple-level piezometer sensors.

Control of the risks from continuing rockfalls caused production delays, and uncertainties in the interpretation of consequences prompted installation of inclinometer casings and updated limit equilibrium and deformation analyses. Radar provided timely warning of an interramp-scale face instability event where debris was trapped on a bench. As immediate control decisions had to be made quickly, there was insufficient time to model the effects of variability in geometry, uncertainties in rock mass strength and stiffness, and the complexities of rock mass structure. While the geotechnical behaviour type remained unclear, the requirements of the monitoring regime were intended to generate evidence that could provide clarification. The frequencies of various measurements were based on the roles that the data played in updating likelihoods. The risk rating remained at the highest level while all this activity took place, with the risk management controls being focussed on achieving acceptable consequences.

High risk scenarios involving uncertainty in behaviour type require as many sources of evidence as possible so that a detailed, self-consistent, quantitative description of behaviour can be developed and tested against equally complex models of expected response. When both consequence and likelihood are uncertain, specialist assistance is required and quality control can be very demanding on resources. Such a level of quality control is justifiable when evidence of high risk is compelling and the geotechnical behaviour type and associated consequences remain unclear but potentially catastrophic. 


\subsection{Managing misunderstandings about high risk}

Awareness of high risk scenarios is based on some combination of usually limited personal experience plus learnings from the experiences of others. For legal and commercial reasons it can be difficult to access the details of what actually contributed to a catastrophic event. There exists a significant specialist literature on the subjects of risk and risk management, which is not referenced here but which can be readily discovered with an internet search engine. The author's experience is most directly with the coal mining industry in Queensland, in relation to which Hopkins (1999) provided a very clear and useful explanation of the contributing factors to an avoidable event that had catastrophic consequences. Lessons that can be readily extrapolated to equivalent excavation control scenarios include:

- There was a failure of decision-making based on cumulative evidence that was generated incrementally and dismissed in isolation without being tested according to oversight procedures and training, and where the actions in response to testing of the evidence would have conflicted with production targets.

- The potential consequence was clearly foreseeable at all times.

- Safety management was pre-occupied with measurable and reportable performance statistics, so that high-frequency/low-consequence actual events received more attention than low-frequency/high-consequence events.

Quality control activities are undertaken against a background where identified hazards with the approved design should be controlled to acceptable levels. Inspections and measurements are intended to identify new hazards or identified hazards with changed risks. The likelihood of an unidentified catastrophic event should be vanishingly small, but that does not mean that the possibility should be ignored. The likelihood of any event can be identified and updated only through the quality control processes of observation, measurement, checking and testing against predictions.

\section{Conclusions}

The original intention of this paper was to undertake a topic review and to illustrate key aspects by highlighting some excavation control and blast damage issues, as well as some experiences with quality control issues. As a consequence of the review process and some concurrent projects, the author is now far less comfortable with many of the practical realities of identifying geotechnical behaviour type for the purposes of risk assessment. The discomfort arose because enabling technologies allow the rapid circulation of large amounts of often incomplete information which more often than not becomes the subject of discussion, comment, and sometimes mistaken actions before being interpreted or tested by appropriately qualified and experienced specialists.

Any implementation project takes place within a management system that the author now thinks of in terms of a living body. Epithets like 'brain-dead' or 'oxygen-starved' come to mind when dealing with the excavation control problem shown in Figure 5. Part of this particular problem was attributable to inadequate assessment of blast damage but the much greater part was inadequate risk management, for which no-one was apparently accountable despite an impressive audit trail for a reputable quality management system. Despite its gloss the quality management system was fundamentally inadequate because there was no ownership of risk when the approved design was implemented. The risk assessment and controls were not updated because routine quality control data was minimal, and not tested for its relevance to slope risks.

Geotechnical practice has gained great benefit from improvements in enabling technologies for excavation control, but we still face significant obstacles to routine implementation of methods for managing blast damage. It is worthwhile to reflect on the enduring legacy of Ralph Peck (Dunnicliffe and Deere, 1991), whose presidential address, on the subject of the direction of our profession to the 8th International Conference on Soil Mechanics in 1973, elaborated on the following points: 
- The most fruitful research grows out of practical problems.

- Geology should be used to greater advantage.

- Our practice falls short of our knowledge.

- Simple calculations based on a range of variables are better than elaborate ones based on limited input.

- Construction deserves more attention in design.

- Instrumentation is no substitute for adequate design.

- We should write with more discrimination.

- Our profession has a challenging future.

The contemporary world of quality management systems is not much different to the one about which Peck was writing, despite the passage of 40 years which have included revolutionary changes in information gathering and transmission with the benefit of robust, compact, and highly personalised portable devices. The intention of quality control processes is to measure outcomes against expectations. The intention of quality assurance systems is to demonstrate a reliable framework for achieving expected outcomes. Quality management systems exist to demonstrate effectiveness of quality assurance and quality control processes. Too much emphasis on the documentation aspects may lead us to overconfidence that processes have been adequately followed and that measurement information has been adequately interpreted. How is the interpretative judgement of an early-career person measured, by the nature of their qualifications or by testing the adequacy of their inspection report? Kahneman (2011) explained why the allegedly more reliable judgement of an experienced person is a function not of age but rather of practice in updating interpretations based on the testing of evidence.

Our enabling technologies, and our human attributes of jumping to conclusions in response to rapid stimuli, have the capability to obstruct the effectiveness of our testing of evidence. Our overriding objective is to implement the design intent. There is much to be gained by devoting less time to collating, distributing, and commenting on information, while using more time to focus on what needs to be measured and tested, and how to do that most efficiently. Peck's final comments in his 1973 address were on the continuing challenges of mechanics, hydraulics, and geology:

"Hence we need never fear that our profession will become routine or dull. If it should, we can rest assured that we would not be practicing it properly".

\section{Acknowledgement}

The organisers of this symposium provided the opportunity to prepare this review and to highlight some issues which have maintained relevance despite decades of technological and organisational changes. Many colleagues contributed, inadvertently at times, to forming the views and opinions expressed herein. Teachers past and present provided enduring reminders of things that should never be taken for granted.

Guidance, encouragement, criticism and support from all of the above people are gratefully acknowledged. Notwithstanding the learnings from and advice of others, all opinions expressed in this paper are the sole responsibility of the author.

\section{References}

Arefi, H., d'Angelo, P., Mayer, H. and Reinartz, P. (2009) Automatic generation of digital terrain models from Cartosat-1 Stereo Images, in Proceedings High-Resolution Earth Imaging for Geospatial Information, C. Heipke, K. Jacobsen, F. Rottensteiner and U. Sörgel (eds), 2-5 June 2009, Hannover, Germany, I Society for Photogrammetry and Remote Sensing, 6 p.

Canbulat, I., Hoelle, J. and Emery, J. (2013) Risk management in open cut coal mines, International Journal of Mining Science and Technology, Elsevier, Vol. 23(3), viewed 26 June 2013, http://dx.doi.org/10.1016/j.ijmst.2013.05.012. 
Cruden, D.M. and Varnes, D.J. (1996) Landslide Types and Processes, Chapter 3 in Landslides Investigation and Mitigation, A.K. Turner and R.L. Schuster (eds), Special Report 247, Transportation Research Board, National Academy Press, Washington, pp. 36-75.

Dunnicliffe, J. and Deere, D.U. (1991) Judgment in Geotechnical Engineering, The Professional Legacy of Ralph B. Peck, BiTech Publishers Ltd, Vancouver, $332 \mathrm{p}$.

Fowler, A. and Kadatskiy, V. (2011) Accuracy and error assessment of terrestrial, mobile, and airborne LiDAR in Proceedings, Annual Conference, American Society for Photogrammetry and Remote Sensing, 1-5 May 2011, Milwaukee, USA, American Society for Photogrammetry and Remote Sensing, Bethesda, $9 \mathrm{p}$.

Haneberg, W.H. (2008) Elevation errors in a LiDAR digital elevation model of West Seattle and their effects on slope stability calculations, R.L. Baum, J. Godt and L. Highland (eds), Landslides and Engineering Geology of the Greater Seattle Area, Washington, Geological Society of America Reviews in Engineering Geology, Geological Society of America, Vol. 20, pp. 55-65, preprint downloadable from www.haneberg.com, viewed 13 June 2013.

Hoelle, J. and Canbulet, I. (2012) A risk rating system for Anglo American's open cut coal mines in Australia, in Proceedings 12th Coal Operators' Conference, 16-17 February 2012, Wollongong, Australia, University of Wollongong and The Australasian Institute of Mining and Metallurgy, pp. 371-377.

Hopkins, A. (1999) Managing Major Hazards, The Lessons of the Moura Mine Disaster, Allen \& Unwin, Sydney, 150 p.

International Organization for Standardization (2008) International Standard ISO 9001:2005, Quality management systems Requirements, International Organization for Standardization, Geneva, viewed 2 June 2013, http://www.iso.org/iso/home/ standards/management-standards/iso_9000.htm.

International Organization for Standardization (2009) International Standard ISO 31000:2009, Risk management Principles and guidelines, International Organization for Standardization, Geneva, viewed 2 June 2013, http://www.iso.org/ iso/home/standards/iso31000.htm.

Kahneman, D. (2011) Thinking, Fast and Slow, Farrar, Straus and Giroux, New York.

Kizil, U. and Tisor, L. (2011) Evaluation of RTK-GPS and Total Station for applications in land surveying, Journal of Earth Systems Sciences, Indian Academy of Sciences, Vol. 120, Number 2, pp. 215-221.

Larkin, B. and Green, D. (2012) CoalLog borehole data standard for the Australian coal industry, ACARP Project C21003, AusIMM, Carlton, viewed 23 June 2013, http://www.ausimm.com.au/content/default.aspx?ID=451.

Lee, J.M., Park, J.Y. and Choi, J.Y. (2013) Evaluation of sub-aerial topographic surveying techniques using Total Station and RTK-GPS for applications in macrotidal sand beach environment, Journal of Coastal Research, Coastal Education \& Research Foundation, Special Issue No.65, pp. 535-540.

Lin, L.S. (2004) Application of GPS RTK and Total Station System on Dynamic Monitoring Land Use, in Proceedings XX International Society for Photogrammetry and Remote Sensing Congress, Technical Commission VII, 12-23 July 2004, Istanbul, Turkey, pp. 302-307.

Norheim, R.A., Queija, V.R. and Haugerud, R.A. (2002) Comparison of LIDAR and INSAR DEMs with dense ground control, in Proceedings, Esri International User Conference, 8-12 July 2002, San Diego, USA, Esri, Redlands, paper 0442, 9 p, viewed 4 June 2013, http://proceedings.esri.com/library/userconf/proc02/pap0442/p0442.htm.

Novak, D. and Baltsavias, E. (2009) Orthoserv - quality assessment for orthorectified and co-registered satellite image products, in Proceedings High-Resolution Earth Imaging for Geospatial Information, C. Heipke, K. Jacobsen, F. Rottensteiner and U. Sörgel (eds), 2-5 June 2009, Hannover, Germany, International Society for Photogrammetry and Remote Sensing, 7 p.

Quality Systems Pty Ltd (2013) Quality Systems Pty Ltd, Brisbane, viewed 12 June 2013, http://www.qualitysystems.com.

Read, J. and Stacey, P. (2009) Guidelines for open pit slope design, CSIRO Publishing, Melbourne.

Scott, A. (1996) Open Pit Blast Design, Monograph 1, Julius Kruschnitt Mineral Research Centre, The University of Queensland, $339 \mathrm{p}$.

Simmons, J.V. and Simpson, P.J. (2006) Composite failure mechanisms in coal measures rock masses - myths and reality, in Proceedings, International Symposium on Stability of Rock Slopes in Open Pit Mining and Civil Engineering, 3-6 April 2006, Cape Town, South Africa, South African Institute of Mining and Metallurgy, Cape Town, pp. 31-49.

Simmons, J.V. and Simpson, P.J. (2007) Extension, stress and composite failure in bedded rock masses, in Proceedings International Symposium on Rock Slope Stability in Open Pit Mining and Civil Engineering (Slope07), Y. Potvin (ed), 12-14 September 2007, Perth, Australia, Australian Centre for Geomechanics, Perth, pp. 213-223.

Simmons, J., Maconochie, P., Larkin, B. and Green, D. (2013) CoalLog: the standard for collection recording storage and transfer of geological and geotechnical data for the Australian coal industry, in Proceedings 2013 Coal Operators' Conference, 14-15 February 2013, Wollongong, Australia, University of Wollongong and The Australasian Institute of Mining and Metallurgy, pp. 9-15.

Standards Australia (2012) Risk Management - Guidelines on Risk Assessment Techniques, Handbook 89-2012, SAI Global Limited, Sydney.

Stewart, I.E., Baynes, F.J. and Lee, I.K. (2002) The RTA Guide to Slope Risk Analysis Version 3.1., Australian Geomechanics, Australian Geomechanics Society, Vol. 37, Number 2, May 2002, pp. 115-147.

Williams, P., Floyd, J., Chitombo, G. and Maton, T. (2009) Design Implementation, Chapter 11, J. Read and P. Stacey (eds), Guidelines for Open Pit Slope Design, CSIRO Publishing, Melbourne, pp. 265-326. 